\title{
Seasonality of Batophora oerstedi (Chlorophyta), a tropical macroalga
}

\author{
Douglas Morrison* \\ Department of Biology, University of Miami, Coral Gables, Florida 33124, USA
}

\begin{abstract}
The seasonality of Batophora oerstedi, a benthic tropical macroalga, was studied in Florida Bay at Key Largo, Florida, USA. Abundance, measured by biomass and coverage sampling. varied seasonally with standing crop highest in summer and fall and lowest in winter. Reproductive activity, expressed as percentage of reproductive individuals, varied seasonally with greatest activity in fall. It is hypothesized that the fall reproductive pulse may be triggered by a drop in water temperature caused by the passage of the first fall cold front or, infrequently, a late summer-early fall hurricane. Net photosynthesis $\left(\mathrm{P}_{N}\right)$ exhibited a unimodal seasonal pattern with highest rates in summer and lowest rates in winter. Net photosynthesis was positively correlated with water temperature, but not significantly correlated with any other environmental parameter. Respiration (R), constant throughout much of the year, was elevated in fall during the period of maximal reproductive activity. The daily (24 h) P/R ratio was always greater than unity suggesting that Batophora is capable of year-round growth.
\end{abstract}

\section{INTRODUCTION}

Recent studies have shown that subtidal, tropical, marine macroalgae exhibit seasonality. Seasonal changes in abundance or standing crop (Dawes et al., 1974; Tsuda, 1974; Josselyn, 1977), growth rate (Bach, 1979; Prince and O'Neal, 1979; O'Neal and Prince, 1982), photosynthesis and respiration (Prince, 1980; O'Neal and Prince, 1982), and reproduction (Dawes et al., 1974; Kaliaperumal and Kalimuthu, 1976; Prince and O'Neal, 1979) have been documented. However, only a few of these studies (Prince and O Neal, 1979; Prince, 1980; O'Neal and Prince, 1982) have concurrently monitored in situ changes in physiological processes and population parameters. Research of this type is needed to understand better the factors responsible for seasonality.

In the present study I monitored abundance, reproductive activity, in situ photosynthetic and respiratory rates of Batophora oerstedi, and selected environmental parameters concurrently from May 1979 through July 1980. This study attempts to interpret population seasonality with respect to physiological processes and environmental factors.

- Present address: Institute of Ecology, University of Georgia, Athens, Georgia 30602, USA
Batophora oerstedi occurs throughout the Caribbean, in the Bahamas, south Florida, Bermuda, and the southern portions of the Gulf of Mexico (Taylor, 1954, 1960). Because of its eurythermal and euryhaline characteristics (Taylor, 1960; Conover, 1964), B. oerstedi is found in a variety of habitats in south Florida. It most commonly occurs on hard substrate immediately below the low tide level in shallow, warm protected lagoonal or bay waters. Here it is often one of the dominant plant species. B. oerstedi appears to be an important macrophyte in the early successional stages of man-made canals in the Florida Keys (Chesher, 1974). Its biology, primarily cytology and development, has been studied by several investigators (e.g. Puiseux-Dao, 1962; Liddle et al., 1976; Bonotto, 1979); however, there is little quantitative information on its ecology.

\section{MATERIALS AND METHODS}

The study area is in Florida Bay at Hammer Point on Key Largo, Florida, USA $\left(25^{\circ} 01^{\prime} \mathrm{N}, 80^{\circ} 30^{\prime} \mathrm{W}\right)$. There are 2 study sites which are about $400 \mathrm{~m}$ apart. One is the bay flat bordering a natural section of the shoreline. It is shallow ( $<1 \mathrm{~m}$ at mean low water [MLW]) and has a 
hard bottom covered by a thin layer (usually $<3 \mathrm{~cm}$ ) of coarse calcareous sediment. The other site is the wall of a man-made canal. It is divided into a shallow ledge (maximum depth: $0.7 \mathrm{~m} \mathrm{MLW}$ ) and a steep slope (maximum depth: $3.3 \mathrm{~m}$ MLW). Only reproductive activity was studied on the slope. Both sites are protected from the prevailing easterly and southeasterly winds, but are exposed to the strong northwest winds accompanying cold fronts.

Quarterly biomass samples were taken from randomly located $0.2 \mathrm{~m}^{2}$ quadrats. Samples were collected in May, early September and November 1979, and in February 1980 on the canal ledge, as well as in early September and November 1979, and early March and May 1980 on the bay flat. In the laboratory, plant material was cleaned of epiphytes and foreign matter, washed with freshwater, and dried at $80^{\circ} \mathrm{C}$ until a constant weight was reached. An additional estimate of Batophora oerstedi abundance came from measurements of percent coverage of substrate surface. Random $0.25 \mathrm{~m}^{2}$ quadrats were sampled along 5 transects that were laid out perpendicular to the shoreline at randomly chosen points. Coverage measurements were taken only in summer (August and early September 1979) and winter (February and early March 1980).

To ascertain seasonal variation in reproductive activity, samples of Batophora oerstedi were taken periodically in 1979 and 1980 on the bay flat, canal ledge, and canal slope. All individuals within randomly positioned quadrats (6 to 10 quadrats/sampling period/location) were removed. In the laboratory, they were cleaned and then separated into vegetative and reproductive portions. Individuals were classified as reproductive if they possessed sporangia visible to the unaided eye. Over 400 individuals were counted in each sampling period.

Productivity measurements were conducted in situ on the canal ledge $(-0.5 \mathrm{~m} \mathrm{MLW})$ at about monthly intervals from July 1978 to July 1980. Plant material was collected by hand immediately prior to an experiment. Individual specimens, immersed at all times, were cleaned of obvious epiphytes and foreign matter. Because Batophora oerstedi reproduces throughout the year, a combination of vegetative and reproductive individuals was used in each experiment. The mean percentage vegetative biomass used was 65.1 (range: 54.2 to 71.1 ). There was no significant difference in the percentage among experiments (ANOVA: $F=1.50$; $\mathrm{df}=15,75 ; \quad \mathrm{P}>0.10$ ). The light-dark bottle oxygen method of estimating primary productivity was used in this study. Dissolved oxygen was measured polarographically with a YSI dissolved oxygen meter (Model 57) and probe-calibrated with water saturated air. Three sets of $0.90 \mathrm{l}$ light-dark containers were used to measure oxygen metabolism. The light containers had ratios of $0.2 \mathrm{~g}$ (dry) plant tissue $\mathrm{l}^{-1}$ seawater or lower to avoid excessive nutrient depletion (Johnston and Cook, 1968; Buesa, 1977) and extreme oxygen supersaturation (Dromgoole, 1978; Littler, 1980). An additional 2 sets of containers served as plankton controls. Each set was attached to a small buoy so that gentle mixing, generated by wave action, of the container water took place. The incubation period was about $4 \mathrm{~h}$ with initiation around $1000 \mathrm{~h}$ EST. Water temperature was measured at the beginning and end of each incubation period. Nutrient and irradiance data were also collected during experiments. After experimentation, the plant material was washed in $10 \%$ acetic acid to remove calcareous particles, rinsed in distilled water, and oven dried at $80^{\circ} \mathrm{C}$ until a constant weight was reached.

Several environmental parameters were measured. A record of maximum and minimum water temperatures was obtained using a Taylor Maximum-Minimum Self-Registering Thermometer located on the bay flat $(-0.4 \mathrm{~m} \mathrm{MLW})$. Readings were taken about every 3 wk. Nutrient samples were taken on the canal ledge during productivity experiments. The samples for nitrate, nitrite, and orthophosphate were fixed with mercuric chloride, those for ammonia with phenol alcohol. All nutrient samples were frozen until analyzed by methods given in Strickland and Parsons (1968). Solar irradiance, surface and submerged $(-0.5 \mathrm{~m} \mathrm{MLW})$, was also recorded on the canal ledge during productivity experiments using a General Electric Radiation Meter (Model 8DW60YZ) in a watertight, glass housing. A continuous record of irradiance in Miami ( $75 \mathrm{~km}$ north of the study area) during the study was abtained from Subtropical Testing Service, Miami, Florida, USA.

\section{RESULTS}

\section{Environmental parameters}

Water temperature at Hammer Point exhibited a unimodal seasonal pattern of considerable amplitude (Fig. 1). Maximum temperature in summer was $36^{\circ} \mathrm{C}$, minimum temperature in winter $12^{\circ} \mathrm{C}$. This large annual range can be attributed to the shallow depths which allow rapid heating and cooling of the water. Also, Key Largo, being near the northern boundary of the tropics, is strongly affected by winter cold fronts. The mean maximum and minimum temperatures in summer (early June to early October) were 34 and $27^{\circ} \mathrm{C}$, respectively, and for winter (mid-December through March) 28 and $16^{\circ} \mathrm{C}$. 


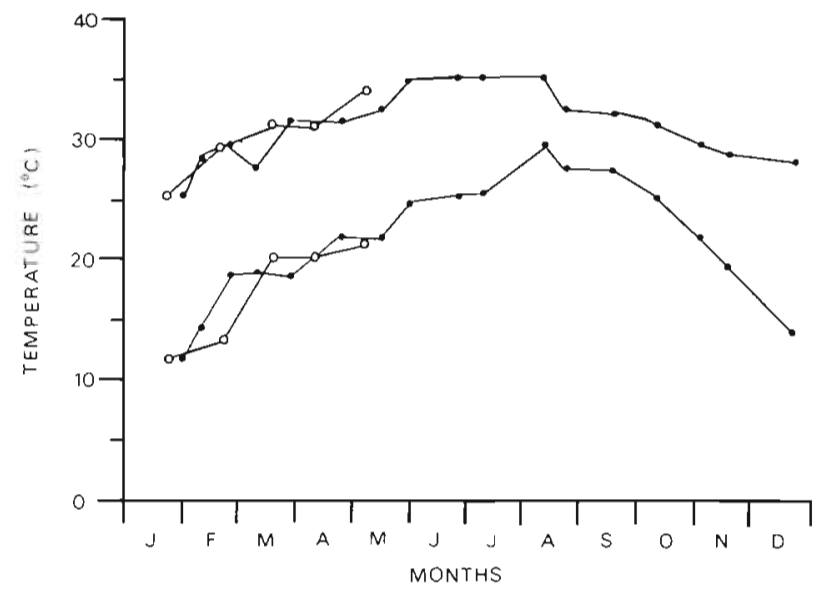

Fig. 1. Maximum and minimum temperatures at Key Largo from January 1979 (•) to May 1980 (o)

Nutrient concentrations varied widely throughout the year with differing patterns (Table 1). Nitrite and nitrate showed no evident seasonal pattern. In general, orthophosphate concentrations were maximal in spring and summer, and ammonia and total inorganic nitrogen $(\Sigma N)$ in summer and fall. The high summer and fall levels coincided with the period of maximum rainfall on Key Largo (Table 1). They may be the result of nutrient influx from terrestrial runoff. Prince and

Table 1. Nutrient concentrations ( $\mu$ g-at $l^{-1}$ ) at Hammer Point and monthly precipitation $(\mathrm{mm})$ at the National Weather Service station, Tavernier, Key Largo. Mean monthly precipitation from 1936 to 1979 given in parentheses

\begin{tabular}{|c|c|c|c|c|c|c|}
\hline Date & $\mathrm{PO}_{4}{ }^{-3}$ & $\mathrm{NO}_{2}^{-}$ & $\mathrm{NO}_{3}^{-}$ & $\mathrm{NH}_{4}{ }^{+}$ & Total N & Precip. \\
\hline $8 / 79$ & & & & & & $138(126)$ \\
\hline $8 / 22 / 79$ & 0.15 & 0.15 & - & 6.57 & - & \\
\hline $9 / 79$ & & & & & & 101 (189) \\
\hline $10 / 79$ & & & & & & 189 \\
\hline $10 / 23 / 79$ & 0.05 & 0.42 & 1.72 & 8.66 & 10.80 & \\
\hline $11 / 79$ & & & & & & $40(52)$ \\
\hline $11 / 26 / 79$ & 0.01 & 0.51 & 4.33 & 8.47 & 13.31 & \\
\hline $12 / 79$ & & & & & & $57 \quad(52)$ \\
\hline $1 / 80$ & & & & & & $19(51)$ \\
\hline $1 / 15 / 80$ & 0.05 & 0.32 & 2.36 & 2.25 & 4.93 & \\
\hline $1 / 23 / 80$ & 0.17 & 0.23 & 1.36 & 2.70 & 4.29 & \\
\hline $2 / 80$ & & & & & & $50 \quad(49)$ \\
\hline $2 / 13 / 80$ & 0.06 & 0.49 & 5.29 & 1.75 & 7.53 & \\
\hline $3 / 80$ & & & & & & $25(46)$ \\
\hline $4 / 80$ & & & & & & $100(58)$ \\
\hline $4 / 17 / 80$ & 0.12 & 0.23 & 2.05 & 2.44 & 4.72 & \\
\hline $5 / 80$ & & & & & & 45 (111) \\
\hline $5 / 05 / 80$ & 0.11 & 0.23 & 1.38 & 2.12 & 3.73 & \\
\hline $5 / 29 / 80$ & 0.13 & 0.72 & 1.58 & 3.17 & 5.47 & \\
\hline $6 / 80$ & & & & & & 116 \\
\hline $6 / 23 / 80$ & 0.19 & 0.45 & 2.84 & 5.30 & 8.59 & \\
\hline $7 / 80$ & & & & & & 129 \\
\hline $7 / 16 / 80$ & 0.10 & 0.15 & 0.92 & 2.78 & 3.85 & \\
\hline
\end{tabular}

O'Neal (1979), on the oceanside of Key Largo, and Segar et al. (1971), in an adjacent bay, found similar nutrient patterns.

Mid-day irradiance data at the study site varied throughout the year, but with little seasonal pattern (Fig. 2). There was a slight peak from late March to mid-May. A continuous record of irradiance in Miami showed a seasonal pattern with highest intensities from March through August, and lowest in December and January (Fig. 3). It appears that mid-day irradiance is more a function of local daily climatic conditions, in particular cloud cover, than seasonal factors.

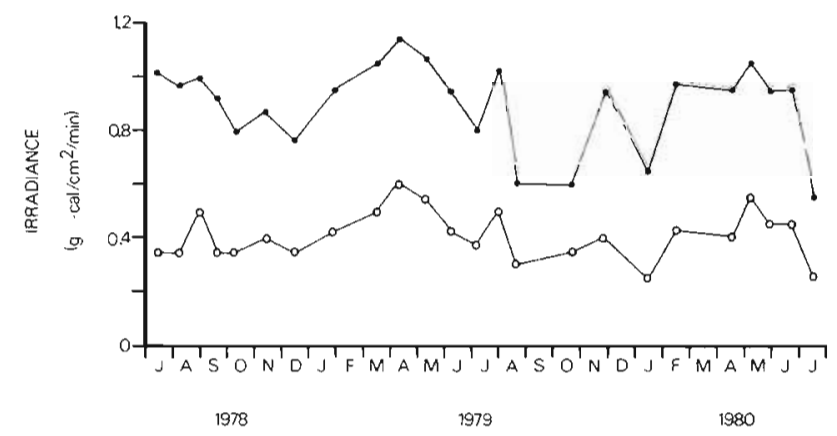

Fig. 2. Mid-day irradiance, surface $(\bullet)$ and submerged (o), on the canal ledge during in-situ productivity measurements on Batophora oerstedi

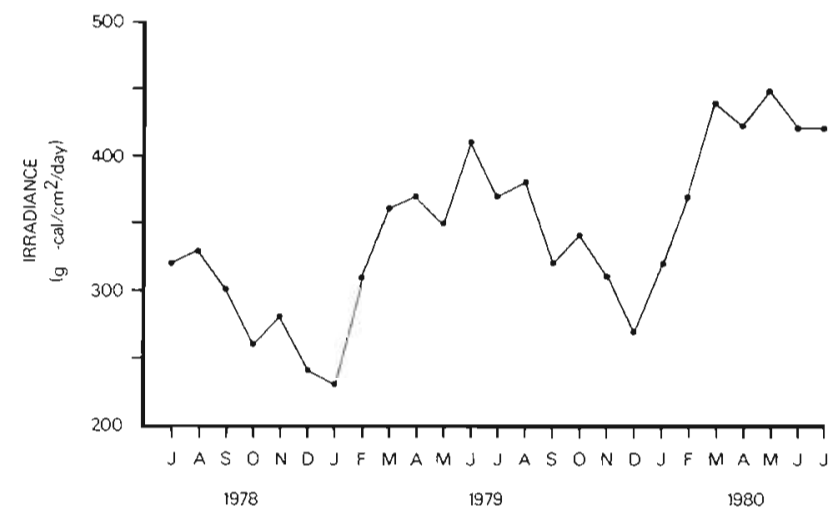

Fig. 3. Mean daily irradiance in Miami during study period. Courtesy of Subtropical Testing Service, Miami

\section{Abundance}

On the bay flat, Batophora oerstedi biomass varied significantly with season (Table 2 ; ANOVA on logtransformed data: $F=11.21 ; d f=3,19 ; P<0.001$ ). A Student-Neuman-Keuls (SNK) multiple range test (Zar, 1974) performed on the sample means revealed that mean biomass in summer and fall was significantly greater $(\mathrm{P}<0.001)$ than in winter and spring. No 
difference was dectected between summer and fall or between winter and spring means. A KolmogorovSmirnov (KS) test (Siegel, 1956) on coverage data also showed a significant difference in abundance $\left(D_{\max }=\right.$ 0.499 ; $\mathrm{P}<0.001$ ), with coverage greater in summer (median $[\mathrm{M}]=30 \%$, range $[\mathrm{R}]: 2-90 \%, \mathrm{~N}=114$ ) than winter $(M=5 \% ; R: 0-60 \%, N=67)$. In terms of biomass (t-test: $t=5.986$, $d f=4, P<0.01$ ) and coverage (test of independence: $X^{2}=12.467, \quad \mathrm{df}=1$, $\mathrm{P}<0.001), B$. oerstedi exhibited zonation in winter with an inner zone (1-8 $\mathrm{m}$ seaward from MLW) of greater abundance. No significant zonation occurred in any other season.

Table 2. Batophora oerstedi. Seasonal biomass (Mean \pm SD [N]) on the canal ledge and bay flat

\begin{tabular}{|c|c|}
\hline Season & Biomass $\left(\mathrm{g}[\mathrm{dry}] \mathrm{m}^{-2}\right.$ ) \\
\hline \multicolumn{2}{|c|}{ Canal Ledge } \\
\hline Spring 1979 & $34.5 \pm 23.8(10)$ \\
\hline Summer 1979 & $79.9 \pm 33.0(10)$ \\
\hline Fall 1979 & $43.9 \pm 18.8(10)$ \\
\hline Winter 1980 & $8.0 \pm 7.0(10)$ \\
\hline \multicolumn{2}{|c|}{ Bay Flat } \\
\hline Summer 1979 & $94.0 \pm 40.4$ \\
\hline Fall 1979 & $111.0 \pm 66.9$ \\
\hline Winter 1980 & $25.3 \pm 22.0$ \\
\hline Spring 1980 & $18.6 \pm 17.4(6)$ \\
\hline
\end{tabular}

On the canal ledge, biomass also varied seasonally (Table 2; ANOVA on log-transformed data: $F=22.80$. $\mathrm{df}=3,36 ; \mathrm{P}<0.001)$. An SNK test revealed that mean biomass was highest in summer $(P<0.025)$ and lowest in winter $(P<0.05)$. No difference was detected between spring and fall means. As on the bay flat, coverage also varied seasonally (KS test: $K_{D}=10, N=$ $17, \mathrm{P}=0.01)$, being greater in summer $(\mathrm{M}=25 \%, \mathrm{R}$ : $5-92 \%, N=17)$ than winter $(M=5 \%, R: 0-45 \%, N$ $=17$ ).

\section{Reproductive activity}

Seasonal reproductive activity expressed as the percentage of reproductive individuals in the population is given in Fig. 4. I found significant seasonality in each habitat (test of independence; bay flat: $\mathrm{X}^{2}=323.88, \quad \mathrm{df}=5, \quad \mathrm{P}<0.001 ; \quad$ canal ledge: $X^{2}=235.27$, $d f=5, P<0.001$; canal slope: $X^{2}=16.88$, df $=5, P=0.002$ ). Reproductive activity was highest in the fall and lowest in summer. In addition to the data presented for 1979 and 1980, this fall reproductive pulse was also observed in a preliminary survey of the canal ledge and bay flat in 1978.

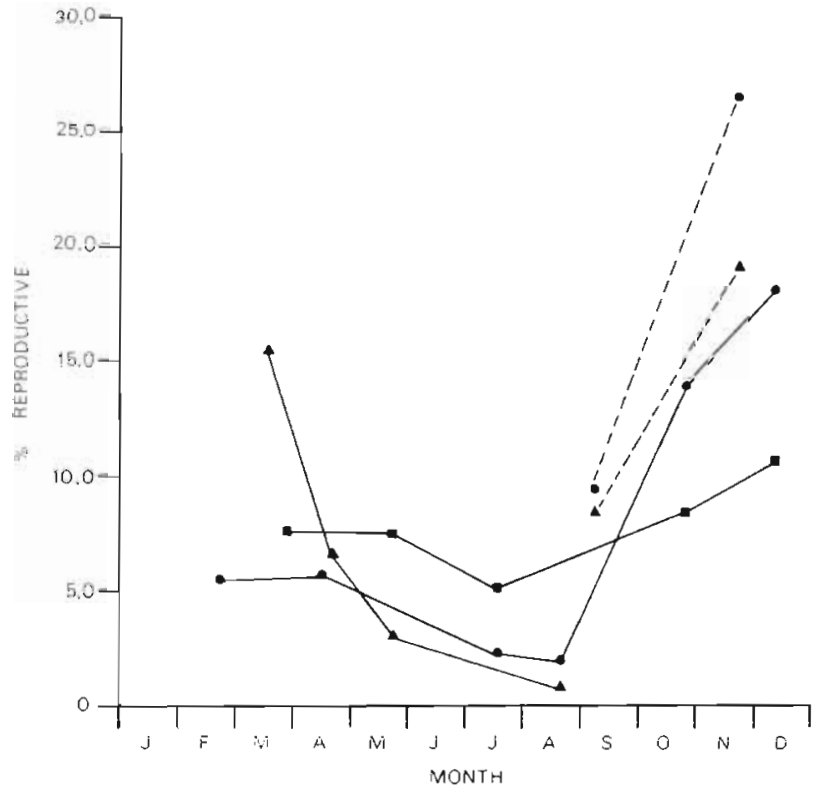

Fig. 4. Batophora oerstedi. Seasonal variation in reproductive activity, expressed as percentage of reproductive individuals in the population. Dashed lines: 1979; solid lines: 1980. (•) Canal ledge, ( $\mathbf{u})$ canal slope, ( $\mathbf{4}$ ) bay flat

In addition to seasonal fluctuations, Batophora oerstedi showed annual and locational differences in reproductive activity. The onset and duration of the fall reproductive pulse varied annually. On the canal ledge, I observed this period to begin in late October, late September, and mid-October in 1978, 1979, and 1980, respectively, and to extend through December. There appeared to be a slight phase shift in the reproductive pulse between sites, with the bay flat lagging behind the canal. Only in that portion of the flat which fringed the canal system did the initiation of this pulse occur simultaneously with the canal. Even by November on the bay flat there was still a zone (MLW to $4 \mathrm{~m}$ seaward) of lower reproductive activity (individuals: $6.6 \%$; biomass: $\overline{\mathrm{x}}=18.9 \%$ ), while $B$. oerstedi on the remainder of the flat exhibited higher activity (individuals: $27.7 \%$; biomass: $\bar{x}=49.0 \%$ ) similar to that on the canal ledge. This phenological zonation is significant using measures of individuals $\left(\mathrm{X}^{2}=83.67\right.$, $\mathrm{df}=1, \quad \mathrm{P}<0.001)$ and biomass $(\mathrm{t}=10.70, \quad \mathrm{df}=4$, $\mathrm{P}<0.001$ ). Reproductive activity on the bay flat was still relatively high in winter 1980 (individuals: $15.4 \%$ ), while on the canal ledge it had dropped to a low level $(5.1 \%)$.

Differences in seasonal reproductive activity with depth also occurred. Although the general patterns on the canal ledge $(-0.5 \mathrm{~m})$ and slope $(-2.2 \mathrm{~m})$ were similar, the amplitude of activity was dampened on the slope. A 3-way independence test (Sokal and Rohif. 1969) showed a significant difference in the magnitude of seasonal change in activity between the ledge and 
slope $(G=31.86$ for interaction term, $d f=2, P<0.001)$. In 1980 reproductive activity increased 8 -fold from summer to December on the ledge, while on the deeper slope it only doubled (Fig. 4)

\section{Photosynthesis and respiration}

Apparent net photosynthesis exhibited a unimodal seasonal pattern (Fig. 5 A). Using physical and biological data (temperature, solar cycle, abundance fluctuations), the year was divided into 4 seasons of varying

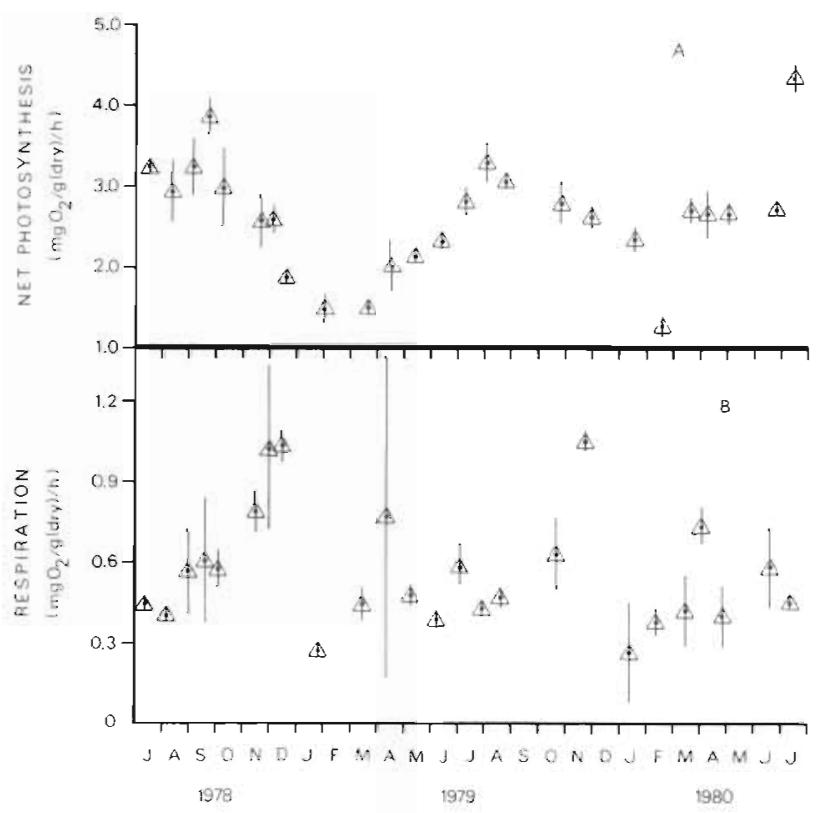

Fig. 5. Batophora oerstedj. In-situ mean apparent net photosynthesis (A) and dark respiration (B) from July 1978 to July 1980. Bars: \pm standard error

duration: summer (mid-June through early October), fall (mid-October to mid-December), winter (midDecember through March), and spring (April to midJune). Data from each season were pooled and subjected to an ANOVA (Table 3). Net photosynthesis $\left(P_{N}\right)$ showed a significant seasonal variation. A StudentNeuman-Keuls (SNK) multiple range test (Zar, 1974) run on the sample means revealed that mean $P_{N}$ was highest in summer $(\mathrm{P}<0.005)$ and lowest in winter $(P<0.001)$. Spring and fall means, which did not differ significantly $(\mathrm{P}>0.10)$, were intermediate. An ANOVA on unpooled data also resulted in a significant difference among samples $(F=9.33$; df $=24,45 ; P<0.001)$, thus verifying that pooling the data did not result in an artificial 'seasonal fluctuation'. $P_{N}$ was positvely correlated with temperature, but was not significantly correlated with any other measured environmental parame-
Table 3. Batophora oerstedi. Comparison of in situ apparent net photosynthetic rates (Mean $\pm \mathrm{SD}[\mathrm{N}]$ ) by season

\begin{tabular}{|c|c|c|c|c|c|}
\hline Season & \multicolumn{4}{|c|}{$\begin{array}{l}\text { Net photosynthesis } \\
\left(\mathrm{mgO}_{2} \mathrm{~g}^{-1}[\mathrm{~d} r \mathrm{y}] \mathrm{h}^{-1}\right)\end{array}$} & \\
\hline Sumrnes & \multirow{4}{*}{\multicolumn{4}{|c|}{$\begin{array}{l}3.27 \pm 0.61(27) \\
2.64 \pm 0.37(11) \\
1.70 \pm 0.44(14) \\
2.40 \pm 0.40(18)\end{array}$}} & \\
\hline Fall & & & & & \\
\hline Winter & & & & & \\
\hline Spring & & & & & \\
\hline \multicolumn{6}{|c|}{ Analysis of variance } \\
\hline Source of variation & $\mathrm{df}$ & SS & MS & $F$ & $\mathrm{P}$ \\
\hline Among groups & 3 & 24.253 & 8.084 & 32.68 & $<.001$ \\
\hline Residual (error) & 66 & 16.329 & 0.247 & & \\
\hline Total & 69 & 40.582 & & & \\
\hline
\end{tabular}

ter (Table 4). Variation in water temperature explained $61 \%$ of the variation in net photosynthesis.

The seasonal pattern for dark respiration differed from that of net photosynthesis (Fig. 5 B). Respiration was fairly constant for most of the year except for an

Table 4. Batophora oerstedi. Correlation coefficients for in situ apparent net photosynthetic rates with selected parameters. Significance levels are determined using the Bernforoni method (After Morrison, 1976)

\begin{tabular}{|lrl|}
\hline Temperature & $0.782(25)^{\mathrm{a}}$ & $\mathrm{P}<0.001$ \\
Irradiance & $-0.400(25)^{\mathrm{a}}$ & $\mathrm{P}>0.20$ \\
Nitrate & $-0.738(9)^{\mathrm{a}}$ & $\mathrm{P}>0.10$ \\
Nitrite & $-0.493(10)^{\mathrm{a}}$ & $\mathrm{P}>0.20$ \\
Ammonia & $0.165(10)^{\mathrm{a}}$ & $\mathrm{P}>0.20$ \\
Total Inorganic N & $-0.085(9)^{\mathrm{b}}$ & $\mathrm{P}>0.20$ \\
Orthophosphate & $0.026(10)^{\mathrm{a}}$ & $\mathrm{P}>0.20$ \\
Respiration & $0.000(25)^{\mathrm{b}}$ & $\mathrm{P}>0.20$ \\
a Product-moment correlation $(\mathrm{N})$ & \\
b Kendal rank correlation $(\mathrm{N})$ & \\
\hline
\end{tabular}

Table 5. Batophora oerstedi. Comparison of in situ dark respiration rates (Mean $\pm \mathrm{SD}[\mathrm{N}]$ ) by phenological period

\begin{tabular}{|c|c|c|c|c|c|}
\hline \multicolumn{3}{|c|}{ Phenological period } & \multicolumn{3}{|c|}{$\begin{array}{l}\text { Dark respiration } \\
\left(\mathrm{mgO}_{2} \mathrm{~g}^{-1}\left[\text { dry] } \mathrm{h}^{-1}\right)\right.\end{array}$} \\
\hline \multicolumn{3}{|c|}{$\begin{array}{l}\text { Maximal reproduction (fall) } \\
\text { Remainder of year }\end{array}$} & \multicolumn{3}{|c|}{$\begin{array}{l}0.87 \pm 0.21 \text { (13) } \\
0.48 \pm 0.22(55)\end{array}$} \\
\hline \multicolumn{6}{|c|}{ Analysis of variance } \\
\hline Source of variation & $\mathrm{d} f$ & SS & MS & $\mathrm{F}$ & $\mathrm{P}$ \\
\hline Among groups & 1 & 1.660 & 1.660 & 34.78 & $<.001$ \\
\hline Residual (error) & 66 & 3.150 & 0.048 & & \\
\hline Total & 67 & 4.810 & & & \\
\hline
\end{tabular}




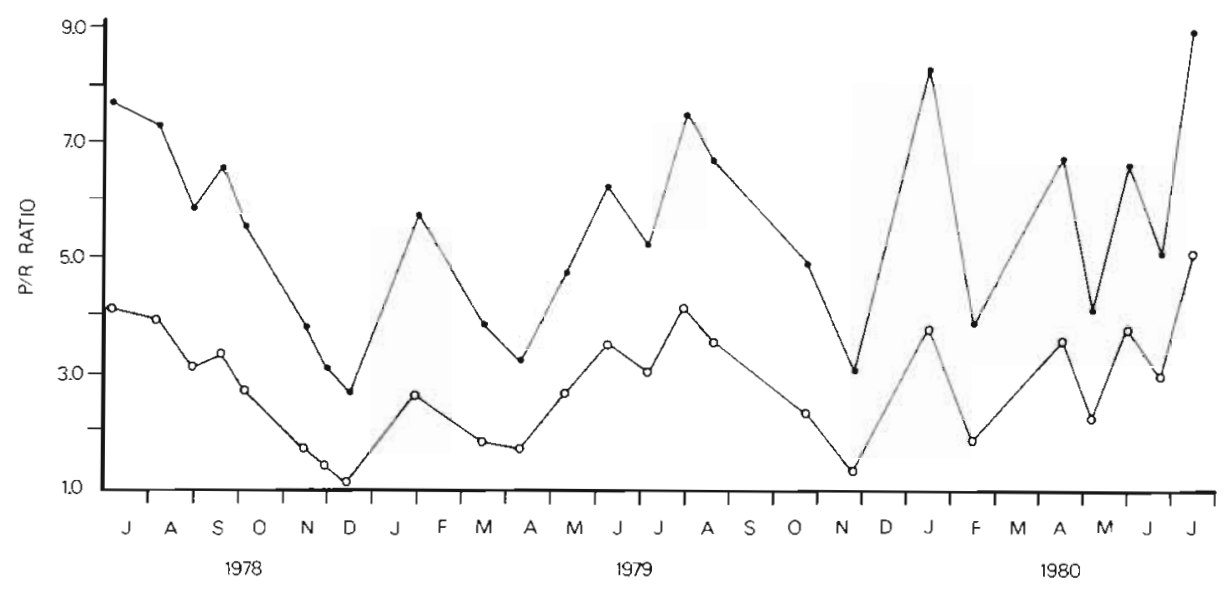

Fig. 6. Batophora oerstedi. Instantaneous (•) and $24 \mathrm{~h}(0)$ gross primary production/respiration (P/R) ratios from July 1978 to July 1980 elevation in fall. Fall was also the period of maximal reproductive activity. The respiration data were pooled into 2 groups: a maximal reproductive period (midOctober through December) and the remainder of the year. An ANOVA conducted on the pooled data showed that respiration was significantly greater during the period of peak reproduction (Table 5).

I calculated instantaneous gross primary production to respiration ratios $(\mathrm{P} / \mathrm{R})$ by converting oxygen values to carbon values using a photosynthetic quotient of 1.2 and a respiratory quotient of 1.0 (Strickland and Parsons, 1968; Hatcher et al., 1977; Hoffman and Dawes, 1980). Using the appropriate daylength, I estimated daily $(24 \mathrm{~h}) \mathrm{P} / \mathrm{R}$ ratios. These daily $\mathrm{P} / \mathrm{R}$ values are approximations because photosynthesis and respiration were measured over only a portion of the day. P/R values were generally highest in summer when $P_{N}$ was high and lowest in fall when respiration was high (Fig. 6). Daily P/R ratios were always greater than 1 , suggesting that Batophora oerstedi is not energy limited and may be capable of growth throughout the year. Conversely, O Neal and Prince (1982) found P/R ratios less than 1 for Caulerpa paspaloides in winter in the Florida Keys.

\section{DISCUSSION}

\section{Abundance}

Batophora oerstedi abundance varied seasonally on the bay flat and canal ledge. Abundance was greatest in summer and fall and lowest in winter. This pattern corresponds closely with that of net photosynthesis. Other investigators have observed changes in benthic macroalgal abundance in the Florida Keys. Bach (1979) found standing crop of Halimeda to be maximal in summer and minimal in winter. Josselyn (1977) reported Laurencia biomass to be greatest in winter and spring and lowest in summer. In addition to
Batophora oerstedi, 9 other species in the Batophoradominated community varied seasonally in abundance (Morrison, 1981).

The fall reproductive pulse and wave action appear to be the primary causes of the winter decline in Batophora oerstedi abundance. Reproductive onset is followed by death. The high percentage of reproductive individuals in fall results in high mortality. The increased wave action with cold fronts causes considerable uprooting in shallow $(<1 \mathrm{~m})$ water. Because net photosynthesis (= growth) is low in winter, the population is not able to replace this lost biomass.

\section{Reproductive activity}

Batophora oerstedi was reproductive throughout the year; however, the intensity of reproductive activity varied seasonally. Several other tropical macroalgae are reproductive all year, including Caulerpa spp. (Goldstein and Morrall, 1970), Acetabularia and other Dasycladaceae (Bernatowicz, 1953; Conover, 1964), and Turbinaria spp. (Unamaheswara Rao and Kalimuthu, 1972; Kaliaperumal and Kalimuthu, 1976). A species may be more successful in a given habitat if there is always some portion of the population in a reproductive state. With propagules always present newly available space may be rapidly colonized. For an annual, which $B$. oerstedi is presumed to be, reproduction and recruitment throughout the year enables the population to replace itself and continually monopolize space. This has been observed for other annual algae (Dayton, 1973; Lubchenco, 1978).

At Hammer Point, peak reproductive activity of Batophora oerstedi was in the fall. Hine (1971) states that in south Florida Caulerpa spp. are reproductive from mid-summer through autumn with greatest activity in October and November. Prince and O'Neal (1979) found Sargassum pteropleuron off Key Largo to be maximally reproductive in November and early 
December. In the lower Keys, Eucheuma spp. exhibited peak reproduction in fall and early winter (Dawes et al., 1974). These studies suggest that in the Florida Keys algal reproductive activity is greatest in fall, however, more research is needed to substantiate this.

Seasonal reproduction in marine macrophytes can be influenced by numerous factors. Photoperiod, temperature, lunar (tidal) cycle, plant maturation, nutrients, and salinity have been shown or suggested to trigger reproduction (Edwards, 1969; Dixon and Richardson, 1970; Dawes et al., 1974; McMillan, 1976. 1980; Gunnill, 1980; Lüning, 1980). These factors can interact as a complex causal network.

Based on the field data, I hypothesize that the fall reproductive pulse of Batophora oerstedi is initiated by an abrupt temperature decrease, perhaps below some
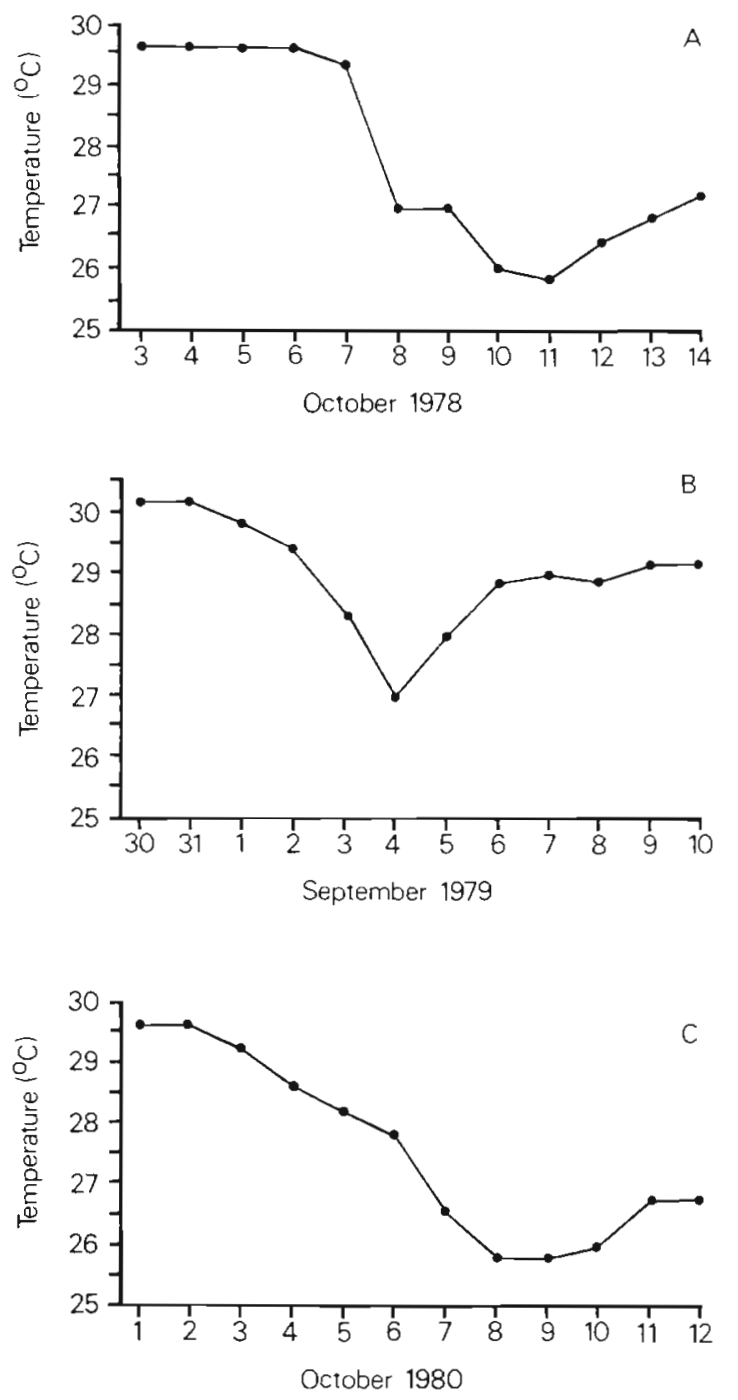

Fig. 7. Mean daily temperature at Pelican Bank in south Biscayne Bay, Florida showing drop in temperature after passage of first fall cold front $(A, C)$ or Hurricane David $(B)$. Courtesy Biscayne National Park critical level. The fall increase in reproduction took place each year; however, its onset varied from year to year. At the canal site, this period began as follows: 1978 - late October; 1979 - late September; 1980 third week of October. The common factor here is the occurrence of a strong storm about $3 \mathrm{wk}$ before the onset of the reproductive pulse. In 1978 and 1980, this was the first fall cold front, and in 1979 it was Hurricane David. Continuous temperature data from Pelican Bank (depth: $1.5 \mathrm{~m} \mathrm{MLW})$ in Biscayne Bay $(50 \mathrm{~km}$ northeast of Hammer Point) showed about a $3 \mathrm{C}^{\circ}$ drop in mean daily temperature within $4 \mathrm{~d}$ following the passage of these storms (Fig. 7). The pre-storm temperatures were remarkably similar in all cases. It is common knowledge that cold fronts passing through south Florida can drop shallow water temperatures dramatically. A hurricane passing close to the area, such as David, can have a similar effect (R. Sheets, US National Hurricane Center, pers. comm.). I suggest that a sudden drop in water temperature caused by the initial fall cold front, or infrequently a late summer hurricane, may trigger the fall reproductive pulse. Other studies on a variety of tropical macrophytes have found an increase in reproductive activity with decreasing water temperature (Rayss, 1955; Hine, 1971; Dawes et al., 1974; DeWreede, 1976; Prince and O'Neal, 1979; McMillan, 1980; Phillips et al., 1981). Several of these investigators (Rayss, DeWreede, McMillan) also speculate that this is the triggering mechanism.

Decreasing daylength is less likely as a triggering agent. Unlike temperature, the daylength in the period immediately preceding reproductive onset differed considerably (range of $1 \mathrm{~h}$ ) among years. Photoperiod is the most annually consistent environmental parameter; thus, it seems unlikely that reproductive onset would annually vary so much if Batophora oerstedi is cueing on daylength. Experimentation is needed to test my hypothesis and determine the relative importance of temperature and photoperiod.

The inherent characters that determine when a plant reaches reproductive maturity can also influence reproductive seasonality. Some species do not produce reproductive structures until they attain a certain size or age (Dawes et al., 1974; Tsuda, 1974). Perhaps individuals must accumulate sufficient photosynthate reserve before initiating reproduction. Liddle et al. (1976) found that Batophora oerstedi in culture does not produce sporangia until it is 4 mo old. The maturation process coupled with excellent colonization ability (Morrison, 1981) could explain why a portion of the population is always reproductive. New additions to the population occur throughout the year. These cohorts reach maturity at different times, thus the apparent continuous reproductive activity in the population. This maturation factor is not inconsistent with 
the proposal of a temperature change triggering the fall reproductive pulse. A large segment of the population appears to reach maturity in September. An abrupt drop in temperature could be the proximal cue for this cohort to initiate reproduction.

\section{Photosynthesis and respiration}

Apparent net photosynthesis $\left(P_{N}\right)$ varied seasonally with highest rates in summer and lowest in winter. Net photosynthesis was significantly correlated with temperature, but not with any other measured environmental parameter. I suggest that temperature is the major cause of seasonality in net photosynthesis. Sargassum pteropleuron, in the Florida Keys, exhibits a similar unimodal seasonal $\mathrm{P}_{\mathrm{N}}$ pattern (Prince, 1980). In field and laboratory studies, O'Neal (1980) found $\mathrm{P}_{N}$ of Caulerpa paspaloides in the Keys to be highly correlated with temperature. He states that low water temperature inhibited net photosynthesis (see also O'Neal and Prince, 1982).

Net photosynthesis was independent of ambient irradiance and nutrient concentrations. Numerous studies have shown that the photosynthetic saturation irradiance for shallow-water algae is much lower than normal ambient intensity (Mathieson and Dawes, 1974; Wanders, 1976; Dawes et al., 1978; Arnold and Murray, 1980; O'Neal, 1980; Ramus and Rosenberg, 1980). Even the lowest average field intensity was well above the saturation intensity for Caulerpa paspaloides (O'Neal, 1980). In controlled experiments, $O$ Neal found that $C$. paspaloides was not nitrogen limited.

Although my study and those of O'Neal (1980) and Prince (1980) indicate that temperature, not irradiance, is the principal determinant of photosynthetic seasonality in the Florida Keys, this observation should not be extrapolated to macroalgae occurring at lower latitudes. At present there are no studies on the photosynthetic seasonality of individual algal species in the central tropics; however, flow respirometry studies on the metabolism of macroalgal and coral reef communities have demonstrated seasonal. variation in primary production (Kinsey, 1977; Adey et al., 1981). These investigators state that irradiance, which is seasonally more variable than temperature at lower latitudes, may be the primary causal factor of photosynthetic seasonality. It appears that temperature acquires greater importance approaching limiting latitudes. Smith's (1981) data on the metabolism of high latitude coral reefs also suggest this.

Respiration also varied seasonally, but exhibited a different pattern from net photosynthesis, with maximum rates occurring in fall during the period of peak reproductive activity. Reproductive onset involves the mobilization of cytoplasm to form reproductive structures. It appears that, at this time, Batophora oerstedi switches from vegetative to reproductive metabolism. Caulerpa prolifera, which also initiates reproduction in the fall in the Florida Keys (Hine, 1971), has a similar respiratory pattern (O'Neal, 1980). O'Neal likewise attributes this pattern to a switch to reproductive metabolism. Similarly, Prahl (1979) found high respiratory rates in sporulating plants. Respiration was independent of ambient water temperature (Kendall rank correlation: $\tau=-0.098, N=25, P>0.50)$. This is true for other species (Newell and Pye, 1968; O'Neal, 1980; Prince, 1980). Newell and Pye attribute this to seasonal respiratory adaptation.

The lack of correlation between net photosynthesis and respiration is evidence for the apparent ecological independence of these physiological functions. Whereas, seasonality in net photosynthesis was influenced by an environmental factor, temperature, seasonal variation in respiration appeared to be the result of a biological phenomenon, reproductive activity, and not directly influenced by abiotic factors. Net photosynthetic, respiratory, and $\mathrm{P} / \mathrm{R}$ values fall in the midrange of those obtained for other tropical green macroalgae (Doty, 1971; Burkholder and Almodovar, 1973; Buesa, 1977).

Conover (1964) has proposed the existence of summer and winter benthic plants, with each group adapted to different environmental conditions, in subtropical regions. The extension of this concept to a more tropical region, specifically the Florida Keys, is supported by several studies (Bach, 1975; Josselyn, 1977; Prince and O'Neal, 1979; Prince, 1980; Morrison, 1981). The results presented here give further evidence for this concept, and suggest that Batophora oerstedi is a summer-adapted plant.

Acknowledgements. This paper is based in part on a thesis submitted in partial fulfillment of the requirements for a M. S. in the Department of Biology, University of Miami. I thank E. R. Rich, J. S. Prince, I. M. Brook, S. W. ONeal, D. P. Janos, and $S$. Green for providing useful discussion and suggestions. S. W. ONeal, J. Mendlein, and T. Vandergon assisted in some of the field work. R. Curry performed some of the nutrient analyses. J. Tilmant supplied unpublished data from studies in Biscayne National Park. I am grateful to J. W. Porter, J. E. Neigel, S. Bonotto, and an anonymous reviewer for helpful criticisms of earlier drafts of this manuscript.

\section{LITERATURE CITED}

Adey, W. H., Rogers, C. S., Steneck, R. S., and Salesky, N. H. (1981). The St. Croix reef: a study of reef metabolism as related to environmental factors and an assessment of environmental management. Report to Dept. Conservation, U.S. Virgin Islands

Arnold, K. E., Murray, S. N. (1980). Relationships between 
irradiance and photosynthesis for marine benthic green algae (Chlorophyta) of differing morphologies. J. exp mar. Biol. Ecol. 43: 183-192

Bach, S. D. (1979). Standing crop, growth, and production of calcareous siphonales (Chlorophyta) in a south Florida lagoon. Bull. mar. Sci. 29: 191-201

Bernatowicz, A. J. (1953). Seasonal changes in the marne algal flora of Bermuda. Univ. Michigan Diss. Ser. Publ. Ann Arbor

Bonotto, S. (1979). Observations on the morphogenesis of Batophora oerstedii. In: Bonotto, S., Kefeli, V., PuiseuxDao, S. (ed.) Developmental biology of Acetabularia. Elsevier Press, Amsterdam, p. 27-34

Buesa, R. J. (1977). Photosynthesis and respiration of some tropical marine plants. Aquat. Bot. 3: 203-216

Burkholder, P. R., Almodovar, L. R. (1973). Studies on mangrove algal communities in Puerto Rico. Fla Scient. 36 66-74

Chesher, R. H. (1974). Canal survey - Florida Keys. Unpublished report, Society for Correlation of Progress and Environment

Conover, J. T (1964). The ecology, seasonal periodicity, and distribution of benthic plants in some Texas lagoons. Botanica mar. 8: 4-41

Dawes, C. J., Mathieson, A. C., Cheney, D. P. (1974). Ecological studies of floridian Eucheuma (Rhodophyta, Gigartinales). I. Seasonal growth and reproduction. Bull. mar. Sci. 24: 235-273

Dawes, C. J., Moon, R. E., Davis, M. A. (1978), The photosynthetic and respiratory rates and tolerances of benthic algae from a mangrove and saltmarsh estuary: a comparative study. Estuar. coast. mar. Sci. 6: 175-185

Dayton, P. K. (1973). Dispersion, dispersal and persistence of the annual intertidal alga Postelsia palmaeformis Ruprect. Ecology 54: 433-438

DeWreede, R. E. (1976). The phenology of three species of Sargassum (Sargassaceae, Phaeophyta) in Hawaii. PhyCologia 15: 175-183

Dixon, P. S., Richardson, W. N. (1970). Growth and reproduction in red algae in relation to light and dark cycles. Ann. N. Y Acad. Sci. 175: 764-777

Doty, M. S. (1971). The productivity of benthic frondose algae at Waikiki Beach, 1967-1968. Univ. Hawaii, Bot. Sci. Paper 22: 1-119

Dromgoole, F. I. (1978). The effects of oxygen on dark respiration and apparent photosynthesis of marine macroalgae. Aquat. Bot. 4: 281-297

Edwards, P. (1969). Field and cultural studies on the seasonal periodicity of growth and reproduction of selected Texas benthic marine algae. Cont. Mar. Sci. Univ. Texas 14: $59-114$

Goldstein, M., Morrall, S. (1970). Gametogenesis and fertilization in Caulerpa. Ann. N.Y Acad. Sci. 175: 660-672

Gunnill, F. C. (1980). Recruitment and standing stock in populations of one green alga and five brown algae in the intertidal zone near La Jolla, California during 1973-1977. Mar. Ecol. Prog. Ser. 3: 231-243

Hatcher, B. G. Chapman, A. R. O., Mann, K. H. (1977). An annual carbon budget of the kelp Laminaria longicruris. Mar. Biol. 44: 85-96

Hine, A. E. (1971). Reproduction of Caulerpa Lamouroux with notes on the life history of certain American species. Ph. D. Dissertation, University of Miami

Hoffman, W. E., Dawes, C. J. (1980). Photosynthetic rates and primary production by two Florida benthic red algal species from a salt marsh and a mangrove community. Bull. mar. Sci. 30: 358-364
Johnston, C. S., Cook, J. P. (1968). A preliminary assessment of the technique of measuring primary production in macrophytic marine algae. Experientia 24: 1176-1177

Josselyn, M. N. (1977). Seasonal changes in the distribution and growth of Laurencia poitei (Rhodophyceae, Ceramiles) in a subtropical lagoon. Aquat. Bot. 3: 217-229

Kaliaperumal, N. Kalimuthu, S. (1976). Changes in the growth, reproduction, alginic acid, and mannitol content of Turbinaria turbinata Bory. Botanica mar. 19: 157-159

Kinsey, D. W. (1977). Seasonality and zonation in coral reef productivity and calcification. In: Taylor, D. L. (ed.) Proceedings of the third international coral reef symposium, Vol. 2. University of Miami, Miami, 383-388

Liddle, L., Berger, S., Schweiger, H. (1976). Ultrastructure during development of the nucleus of Batophora oerstedii (Chlorophyta; Dasycladaceae). J. Phycol. 12: 261-272

Littler, M. M. (1980). The effects of bottle volume, thallus weight, oxygen saturation levels, and water movement on apparent photosynthetic rates in marine algae. Aquat. Bot. 7: $21-34$

Lubchenco, J. (1978). Plant species diversity in a marine intertidal community: importance of herbivore food preference and algal competitive abilities. Am. Nat. 112: 23-39

Lüning, K. (1980). Control of algal life-history by daylength and temperature. In: Price, J. H., Irvine, D., Farnham, W.E. (ed.) The shore environment, Vol. 2, Ecosystems. Academic Press, London, p. 915-945

Mathieson, A. C., Dawes, C. J. (1974). Ecological studies of floridean Eucheuma. II. Photosynthesis and respiration. Bull. mar. Sci. 24: 274-285

McMillan, C. (1976). Experimental studies on flowering and reproduction in seagrasses. Aquat. Bot. 2: 87-92

McMillan, C. (1980). Flowering under controlled conditions by several seagrasses from Kenya. Aquat. Bot. 8: 323-336

Morrison, D. E. (1981). Macroalgal seasonality in Batophoradominated communities in the Florida Keys. M. S. thesis, University of Miami

Morrison, D. F. (1976). Multivariate statistical methods, 2nd ed. McGraw-Hill, New York

Newell, R. C., Pye, V. I. (1968). Seasonal variation in the effects of temperature on the respiration of certain intertidal algae. J. mar. biol. Ass. U.K., 48: 341-348

O'Neal, S. W. (1980). The ecological physiology of the siphonaceous marine alga Caulerpa paspaloides (Chlorophyta) in the waters off south Florida. Ph. D. Dissertation, University of Miami

O'Neal, S. W., Prince, J. S. (1982). Relationship between seasonal growth, photosynthetic production and apex mortality of Caulerpa paspaloides (Chlorophyceae). Mar. Biol. 71: 61-67

Phillips, R. C., McMillan, C., Bridges, K. W. (1981). Phenology and reproductive physiology of Thalassia testudinum from the western tropical Atlantic. Aquat. Bot. 11: 263-277

Prahl, C. (1979). Photosynthesis and respiration in some littoral marine algae from Greenland (note). Phycologia 18: $166-168$

Prince, J. S. (1980). The ecology of Sargassum pteropleuron Grunow (Phaeophyceae, Fucales) in the waters off south Florida. II. Seasonal photosynthesis and respiration of S. pteropleuron and comparison of its phenology to that of S. polyceratium Montague. Phycologia 19: 190-193

Prince, J. S., O'Neal, S. W. (1979). The ecology of Sargassum pteropleuron Grunow (Phaeophyceae, Fucales) in the waters off south Florida. I. Growth, reproduction, and population structure. Phycologia 18: 109-114

Puiseux-Dao, S. (1962). Recherches biologiques et physiologi- 
ques sur quelques Dasycladaces, en particulier, le Batophora oerstedii et Acetabularia mediterranea. Revue gen. Bot. 819: 409-503

Ramus, J., Rosenberg, G. (1980). Diumal photosynthetic performance of seaweeds measured under natural conditions. Mar. Biol. 56: 21-28

Rayss, T (1955). Les algues marines des cotes Palestiniennes I. Chlorophyceae. Bull. Sea Fish. Res. Stn Israel 9: 1-36

Segar, D., Gerhakov, S., Johnson, T. (1971). Chemistry. In: Bader, R., Roessler, M. (ed.) An ecological study of south Biscayne Bay and Card Sound. Prog. Rept. U.S. Atomic Energy Comm. and Fla. Power Light, Univ, Miami, Miami, p. IV $-1-I V-64$

Siegel, S. (1956). Nonparametric statistics for the behavioral sciences. McGraw-Hill, New York

Smith, S. V. (1981). The Abrolhos Islands: carbon metabolism of coral reefs at high latitude. Limnol. Oceanogr. 26; $612-621$

Sokal, R. R., Rohlf, F. J. (1969). Biometry. W. H. Freeman Co., San Francisco

Strickland, J. D. H., Parsons, T. R. (1968). A practical hand- book of seawater analysis. Bull. Fish. Res. Bd Can. 167 $1-311$

Taylor, W. R. (1954). Distribution of marine algae in the Gulf of Mexico. Pap. Mich. Acad. Sci. 39: 85-109

Taylor, W. R. (1960). Marine algae of the eastern tropical and subtropical coasts of the Americas. Univ. Mich., Stud. Sci. Ser. 21: $1-870$

Tsuda, R. T (1974). Seasonal aspects of the Gaum Phaeophyta (brown algae). In: Cameron, A. M. (ed.) Proceeding of the second international symposium on coral reefs, Vol. 1. Great Barrier Reef Committee, Brisbane, Australia, p. $43-47$

Unamaheswara Rao, M., Kalimuthu, S. (1972). Changes in mannitol and alginic acid contents of Turbinaria ornata (Turner) J. Agardh in relation to growth and fruiting. Botanica mar. 15: 57-59

Wanders, J. B. W. (1976). The role of benthic algae in the shallow reef of Curaçao (Netherlands Antilles). I. Primary productivity in the coral reef. Aquat. Bot. 2: 235-270

Zar, J. H. (1974). Biostatistical analysis. Prentice Hall, Inc., Englewood Cliffs, N. J.

This paper was submitted to the editor; it was accepted for printing on August 1, 1983 